\title{
Detection of Second Mesiobuccal Canals in Maxillary First Molars Using a New Angle of Cone Beam Computed Tomography
}

\author{
Ali Murat Aktan,, ${ }^{1,}$ Cihan Yildirim, ${ }^{2}$ Emre Culha, ${ }^{3}$ Erhan Demir, ${ }^{4}$ and Mehmet Ertugrul Ciftci ${ }^{5}$ \\ ${ }^{1}$ Department of Dentomaxillofacial Radiology, Faculty of Dentistry, University of Ușak, Ușak, Turkey \\ ${ }^{2}$ Department of Endodontics, Faculty of Dentistry, University of Gaziantep, Gaziantep, Turkey \\ ${ }^{3}$ Department of Endodontics, Faculty of Dentistry, University of Zirve, Gaziantep, Turkey \\ ${ }^{4}$ Department of Endodontics, Faculty of Dentistry, University of Marmara, Istanbul, Turkey \\ ${ }^{5}$ Department of Dentomaxillofacial Radiology, Faculty of Dentistry, University of Akdeniz, Antalya, Turkey \\ "Corresponding author: Ali Murat Aktan, Department of Dentomaxillofacial Radiology, Faculty of Dentistry, University of Ușak, Ușak, Turkey. Tel: +90-5327074499, E-mail: \\ alimurataktan@yahoo.com
}

Received 2015 June 30; Revised 2015 September 07; Accepted 2015 September 14.

\begin{abstract}
Background: The localization of the additional canal orifice is one of the primary factors influencing the success of endodontic treatment. To deal with this problem, several techniques that each have their own advantages and disadvantages have been discussed in the literature.

Objectives: The aim of the present in vitro study was to review a new approach to localizing second mesiobuccal (MB2) canals in maxillary first molars using cone beam computed tomography (CBCT).

Patients and Methods: The CBCT scans of 296 patients who were referred to the department of dentomaxillofacial radiology were included in the study. The presence of MB2 canals, the angle formed by the mesiobuccal, distobuccal, and palatal root canal orifices $(\angle \mathrm{MDP})$, and the angle formed by the mesiobuccal, distobuccal, and MB2 canal orifices ( $\angle \mathrm{MDMB} 2$ ) were evaluated on the axial section. Pearson correlation and multiple linear regression methods were used for all predictions. All of the analyses were performed using SPSS for windows version 22.0. A two-sided P value $<0.05$ was defined as statistically significant.

Results: Of the 468 first molars, MB2 canals were observed in 296 subjects (141 females and 155 males). There were no statistically significant differences between females and males $(\mathrm{P}=0.300)$. The $\angle \mathrm{MDP}$ and $\angle \mathrm{MDMB} 2$ were detected and evaluated. A moderate positive correlation was found between the $\angle$ MDP and the $\angle$ MDMB2. To predict the $\angle$ MDMB2 values, it was shown that the $\angle$ MDMB2 increased by 0.420 degrees when the $\angle$ MDP increased by 1 degree. If the $\angle$ MDP was greater than 90.95 degrees, there was a $78 \%$ probability that MB2 canals could be found.

Conclusion: The determination of the presence of MB2 in the maxillary first molars may be carried out using CBCT scans. If the $\angle \mathrm{MDP}$ was 91 degrees or greater, there was considered to be a higher probability that MB2 canals would be found in the endodontic cavity. Due to the positive correlation between the $\angle$ MDP and the $\angle$ MDMB2, the localization of MB2 canals may be easily performed in relation to the main MB canal.
\end{abstract}

Keywords: Cone Beam Computed Tomography, Root Canal Therapy, Endodontics

\section{Background}

The meticulous cleaning, shaping, and filling of the root canal systems are the primary aims of root canal treatment (1). The maxillary first molar tooth has one of the most complex root and canal anatomies $(2,3)$. Countless studies and discussions have been based on the existence of a second canal in the mesiobuccal (MB) root of the maxillary molars $(4,5)$, since it is strongly believed that one of the foremost reasons for endodontic failure in maxillary first molars is the difficulty of detecting and treating those second mesiobuccal (MB2) canals (2).

Several techniques have been used to detect MB2 canals in maxillary molars in both in vitro and clinical studies, including operating microscopes (6-11), ultrasounds (12), the use of a bur and explorer $(10,13)$, and conventional or advanced radiographic techniques (14-18). Such approaches are commonly used to facilitate the detection of MB2 canals $(10,19,20)$; however, the abovementioned methods cannot reliably detect MB2 canals (15). The literature reveals that although MB2 canals of maxillary first molars have been found in more than $70 \%$ of in vitro studies $(5,7,21,22)$, they were detected clinically in less than $40 \%$ of cases $(2,23-25)$. Cone beam computed tomography (CBCT) is a new technology in the field of endodontics that has several advantages, including the ability to perform three-dimensional (3D) imaging of root canal systems with 
lower radiation doses, higher resolution, and no superimposition (26-28). Therefore, CBCT could be useful for several common endodontic fields, including endodontic surgery, dental trauma, internal or external root resorption, diagnosis of apical pathosis, and evaluation of the complex root canal configuration (29-32).

\section{Objectives}

Researchers have evaluated the efficiency of CBCT when it comes to identifying MB2 canals, and СВCT has been suggested to be a reliable method for the detection of these canals (4), while other authors have considered the localization of MB2 canals using CBCT scans (14). However, few studies with sufficient and satisfactory findings regarding the localization of MB2 canals using CBCT could be found in the literature. Therefore, the aim of the present in vitro study is to develop a new approach for localizing MB2 canals in the maxillary first molars using CBCT. This method could facilitate the detection of MB2 canals in clinical practice.

\section{Patients and Methods}

This retrospective study included CBCT data from patients who were referred to the department of dentomaxillofacial radiology, faculty of dentistry, Gaziantep, Turkey, from 2011 to 2014. The CBCT data were recorded for several reasons, including implant surgery, pathological reasons, or orthodontic treatment. A total of 468 maxillary first molars were investigated from 296 patients ( 155 males and 141 females) with a mean age of $24.42( \pm 11.29)$ years (range 7 68 years).

Maxillary first molar teeth with no caries or defects, filled materials, periapical lesions, root canal treatments, or root canals with open apices, resorption, or calcification were evaluated to prove that reliable, good quality CBCT images were available. Any cases of the abovementioned conditions were excluded from the study since they may adversely affect the image quality. All of the CBCT images were obtained using the same scanner (Planmeca, Promax, Helsinki, Finland). Axial, sagittal, and coronal sections were imaged, and the images were analyzed using special CBCT software (Romexis, Planmeca, Helsinki, Finland). The study was approved by the local ethics committee of the university of Gaziantep.

All of the images from 296 maxillary molar teeth were evaluated on the axial section. Using the axial section as a guide allowed the accurate localization of the designated parameters without superimposition in different planes.
Thus, the reproducibility of the measurements was ensured by the use of such standardization (33). The first axial section where the angles formed by the canal orifices were seen from the axial plane was used to determine the angles used in the present study. In fact, there was no final decision on this matter in the literature. The following parameters were recorded: the presence of MB2 canals; the angle formed by the mesiobuccal, distobuccal, and palatal root canal orifices ( $\angle \mathrm{MDP})$; and the angle formed by the mesiobuccal, distobuccal, and MB2 canal orifices ( $\angle$ MDMB2). The presence of MB2 was analyzed according to age, gender, and side (right or left) where the MB2 canals were identified. In addition, the $\angle$ MDP and the $\angle$ MDMB2 were analyzed and evaluated.

All of the measurements and analyses were performed twice by one dentomaxillofacial radiologist (AMA) and one experienced endodontist (EK), with a two-week interval between the assessments. If there was any disagreement in the results, they were discussed and a final decision was made. All data were obtained after the final calibration. A consensus was reached between the radiologist and the endodontist as to how many canals were present in the $\mathrm{MB}$ root of the tooth in question, as well as to how the $\angle \mathrm{MDP}$ and $\angle \mathrm{MDMB} 2$ angles were measured on the $\mathrm{CBCT}$ scans (Figure 1). The observations were carried out under dimmed lighting and against a black background. The images were viewed on a 24 inch ultrasharp LED TFT monitor (Dell, USA) that displayed 2 megapixels, with a 0.27 pixel pitch.

To compare the two groups, Student's t-test (for continuous variables), the chi-squared test (for categorical variables), and Pearson correlation (for two numerical variables) were used. Next, a multiple linear regression model was employed for the predictions. The intra- and interobserver agreements were calculated using the interclass correlation coefficient (ICC). Means and standard deviations were given as descriptive statistics. All analyses were performed using SPSS for Windows version 22.0 (IBM Corp. Released 2013. IBM SPSS Statistics for Windows, Version 22.0. Armonk, NY: IBM Corp.). A two-sided P value $<0.05$ was considered as statistically significant.

\section{Results}

Data were obtained from 728 patients, and 468 maxillary first molar teeth in 296 subjects ( 155 males and $141 \mathrm{fe}$ males) were investigated in this retrospective CBCT-based study. The age range of the subjects was 7 to 68 years, while the mean age was 24.42 years $( \pm 11.29)$. Of the 468 first molars, 205 MB2 canals were observed. Of those, 103 MB2 canals were in males and 102 were in females. The incidence of MB2 canals was found to be $43.80 \%$. There were no 

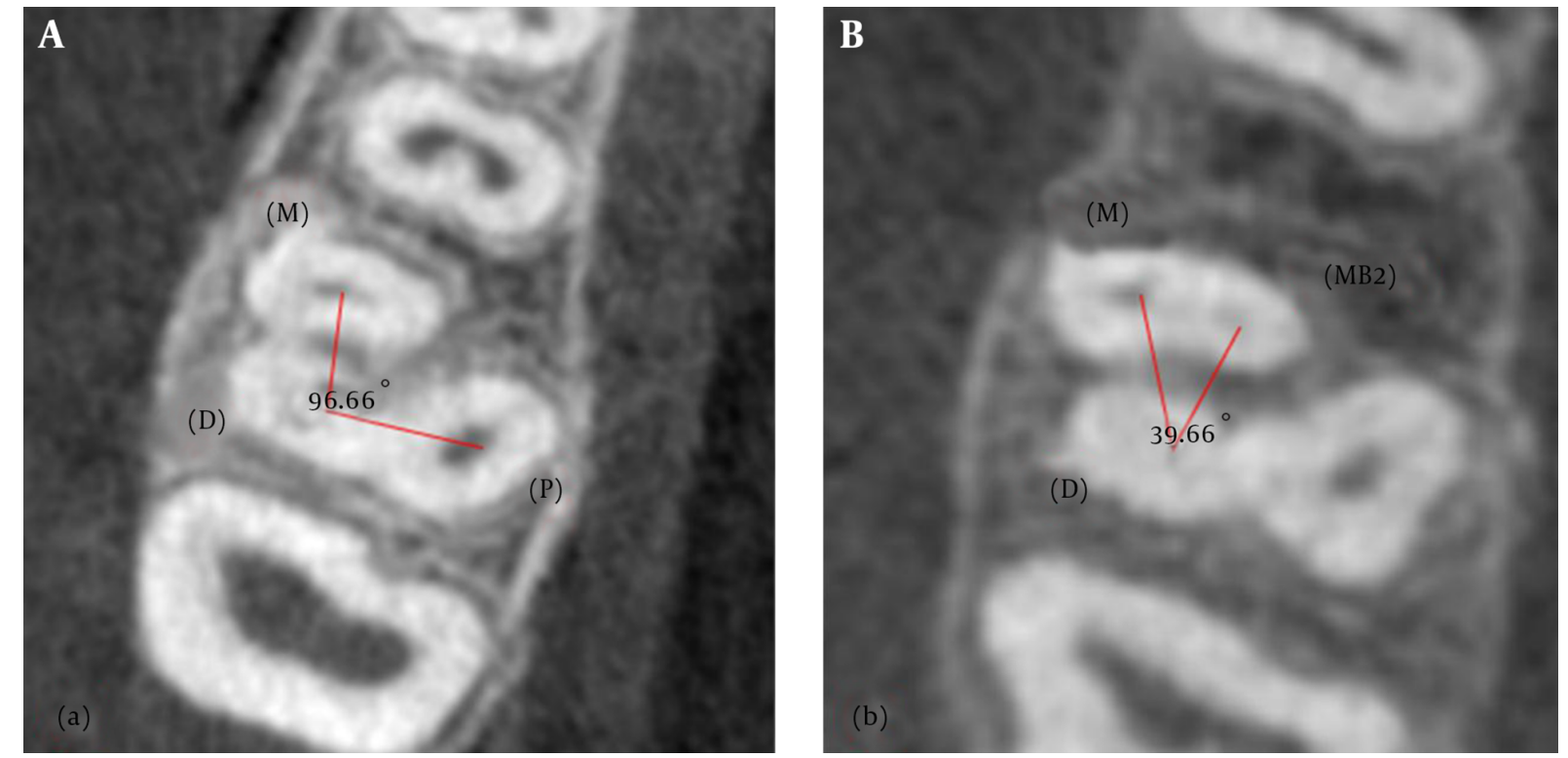

Figure 1. Illustration of the $\angle \mathrm{MDP}$ and the $\angle \mathrm{MDMB} 2$ in the axial slice of first molar teeth

statistically significant differences according to the gender of the patients $(\mathrm{P}=0.300)$ (Table 1$)$. The ICC scores of the observers, AMA and EK, were found to be 0.862 and 0.901 for the intra-observer agreements, and the ICC was also found to be 0.759 for the inter-observer agreement.

The $\angle$ MDP and the $\angle$ MDMB2 were also detected and evaluated in the current study. The maxillary first molar teeth with MB2 canals had a statistically significant higher $\angle$ MDP than the teeth without MB2 canals (Table 2). A moderately positive correlation was found between the $\angle \mathrm{MDP}$ and the $\angle$ MDMB2 (Figure 2). To predict the $\angle$ MDMB2 values in the multiple regression model, it was shown that the $\angle$ MDMB2 increased by 0.420 degrees when the $\angle M D P$ increased by 1 degree (Figure 2 ), and this could be formulated as $\mathrm{Y} \angle \mathrm{MDMB} 2=0.420 \times \angle \mathrm{MDP}\left(\mathrm{r}^{2}=0.309\right)$.

\section{Discussion}

One of the most important factors that leads to the failure of root canal therapy is the inability to effectively treat all canals in the root canal system (4). Failure to find and obturate the MB2 canals in permanent maxillary first molars has been proven to pose the greatest challenge to adequate endodontic treatment, and it will likely result in the failure of the treatment as a whole $(9,34)$. In fact, the evidence to date suggests that more MB2 canals are found in laboratory studies (approximately 70\%) than in clinical practice (approximately $40 \%$ ) (35), although microsurgical

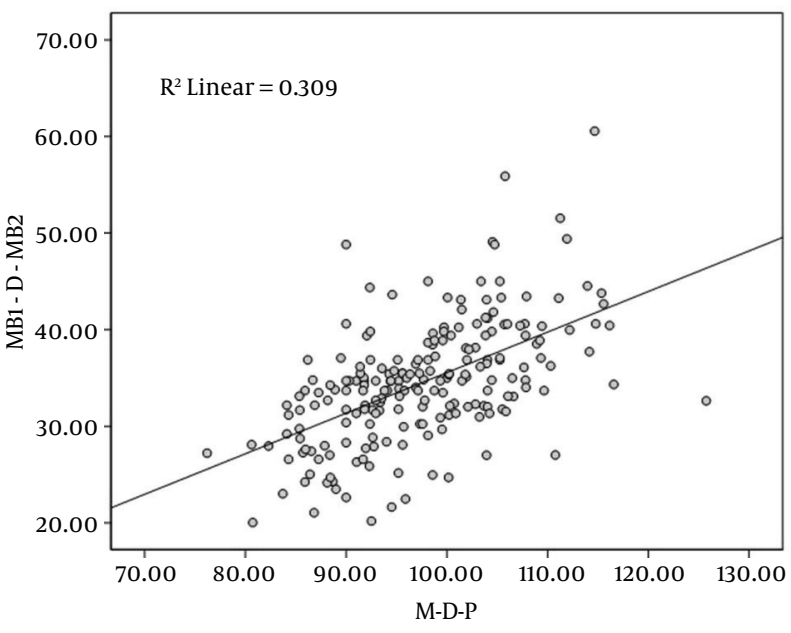

Figure 2. The correlation between the $\angle \mathrm{MDP}$ and the $\angle \mathrm{MDMB} 2$ in the localization of MB2 canals in maxillary first molars

instruments such as magnifying loupes and dental operating microscopes are commonly used to increase the detection rate of MB2 canals in clinical situations (9). Threedimensional imaging of teeth with MB2 canals prior to endodontic treatment may help to increase the success rate of root canal therapy. While micro-CT facilitates endodontic studies in the laboratory (36), CBCT scans may be useful in clinical settings due to advantages such as lower radiation dose (37-39), higher resolution (39), and isotropic vox- 
Table 1. The Gender Distribution of the Presence or Absence of MB2 Canals According to Subjects and Teeth

\begin{tabular}{|c|c|c|c|c|}
\hline & Presence or Absence & Females (\%) & Males (\%) & Total (\%) \\
\hline \multirow{3}{*}{ Subjects } & MB2 Presence ${ }^{\mathrm{a}}$ & $131(62.68)$ & $78(37.32)$ & $209(100.00)$ \\
\hline & MB2 Absence & $95(55.23)$ & $77(44.77)$ & $172(100.00)$ \\
\hline & Total & $141(47.64)$ & $155(52.36)$ & $296(100.00)$ \\
\hline \multirow{2}{*}{ Teeth } & MB2 Presence & $102(49.76)$ & $103(50.24)$ & $205(100.00)$ \\
\hline & Total & $226(48.3)$ & $242(51.7)$ & $468(100.00)$ \\
\hline Pvalue & & \multicolumn{3}{|c|}{0.300} \\
\hline
\end{tabular}

Abbreviation: MB2, second mesiobuccal canal.

${ }^{\mathrm{a}} \mathrm{MB} 2$ was found on at least one side.

Table 2. Increase of $\angle$ MDP in the Presence of MB2 Canals

\begin{tabular}{|c|c|c|c|c|c|}
\hline & $\mathbf{N}$ & $\angle$ MDP, Mean, Degree & Std. Deviation & $\mathbf{P}$ & $\mathbf{r}$ \\
\hline MB2 Absence & 262 & 93.8606 & 11.29781 & 0.001 & 0.556 \\
\hline MB2 Presence & 205 & 97.6326 & 8.37563 & & \\
\hline
\end{tabular}

Abbreviation: MB2, second mesiobuccal canal.

els (40). In a pilot study, Blattner et al. (4) assessed CBCT scans' ability to accurately confirm or disconfirm the existence of MB2 canals in maxillary first molars. They found that CBCT scanning is a reliable method of detecting MB2 canals. In light of these studies as well as continuing technological advancements, researchers have focused on producing more accurate CBCT scans with better quality imaging of MB2 canals, which will facilitate the diagnosis of previously untreated MB2 canals. The results of the present study showed the detection rate for MB2 canals to be $44 \%$, which is approximately consistent with the results of previous clinical studies (7).

The prevalence and factors affecting the identification of MB2 canals in maxillary molars have been examined in many studies $(11,41)$. However, little research has been conducted on MB2 canal localization in relation to the main MB canal $(5,42)$. Researchers found the mean distance of the MB2 canal and the mean distance of the MB2 orifice from the main MB orifice to be $2.31 \mathrm{~mm}$ and $1.82 \mathrm{~mm}$, respectively. Gorduysus et al. (7) and Zhang et al. (43) noted that the location of MB2 canals did not only vary in relation to the main MB canal, but rather that the palatal canal orifice could be used as another reference point. Zhang et al. (43) reported that MB2 canals are located less than $1 \mathrm{~mm}$ mesially to the MB-P line and $2 \mathrm{~mm}$ palatally from the MB orifice. Moreover, Gorduysus et al. (7) investigated the location of MB2 canals and found these measurements to be $0.69 \mathrm{~mm}$ mesially and $1.65 \mathrm{~mm}$ palatally. These linear mea- surements of the abovementioned reference points suggest that the determination of the MB2 canal may be related to the success or failure of root canal treatment. As the linear measurements can vary from tooth to tooth, it was hypothesized that there may be an angular relationship between the reference points in the present study. The possible correlation between the existence of MB2 canals and the angles formed by the reference points, including the mesiobuccal, distal, and palatal orifices ( $\angle$ MDP), was investigated in the present study. Since an $\angle$ MDP greater than 90.95 degrees points to the existence of MB2 canals, clinicians can use this information to predict whether MB2 canals are present. The results will therefore contribute to the literature and facilitate the clinical identification of MB2 canals in maxillary first molar teeth.

The relationship between the $\angle$ MDP and the $\angle$ MDMB2 was also investigated in this study. According to the results, there was a strong positive relation between the $\angle$ MDP and the $\angle$ MDMB2. It was found that the $\angle$ MDMB2 increased by 0.420 degrees when the $\angle$ MDP increased by 1 degree (Figure 2). These results offer the opportunity to use the $\angle \mathrm{MDP}$ in order to predict the $\angle$ MDMB2. To the best of our knowledge, only one study has previously been performed in relation to the $\angle \mathrm{MDP}(14)$. Here, the authors indicated that in teeth with an $\angle$ MDP greater than 140 degrees, the MDMB2 orifice will be located closer to the line connecting the $\mathrm{MB}$ orifice with the palatal orifice (14). In the present study, it was suggested that the MDMB2 orifice could be found 
more easily via angular evaluation. This also supported Han et al.'s suggestion (14).

There were some limitations to the present study. First, the presence of $\mathrm{MB} 2$ in relation to the angles and, second, the reliability of the CBCT scans regarding the determination of accessory canal orifices could not be checked in this retrospective study, since it was not based on clinical or in vitro conditions. Finally, it was assumed that CBCT observations of a 4 th canal are $100 \%$ reliable, although the teeth were not checked clinically or histologically. For that reason, the measurements in the present study may be varied according to the accuracy of the CBCT scans. In the light of these limitations, further studies are needed.

Bearing in mind the limitations of the present study, it could be concluded from the results that if the $\angle \mathrm{MDP}$ is more than 90.95 degrees, the possibility of MB2 canals in the endodontic cavity should be investigated. Due to the positive correlation between the $\angle$ MDP and the $\angle$ MDMB2, the localization of MB2 canals may be performed easily with reference to the main MB canal. Further studies on the localization of MB2 canals are needed in order to achieve a more reliable method.

\section{Footnotes}

Authors' Contribution: None declared.

Financial Disclosure: None declared.

Funding/Support: None declared.

\section{References}

1. Tuncer AK, Haznedaroglu F, Sert S. The location and accessibility of the second mesiobuccal canal in maxillary first molar. Eur J Dent. 2010;4(1):12-6. [PubMed: 20046474].

2. Alacam T, Tinaz AC, Genc O, Kayaoglu G. Second mesiobuccal canal detection in maxillary first molars using microscopy and ultrasonics. Aust Endod J. 2008;34(3):106-9. doi: 10.1111/j.1747-4477.2007.00090.x. [PubMed: 19032644].

3. Vertucci FJ, Haddix JE, Britto LR. Tooth morphology and access cavity preparation. In: Cohen S, Hargreaves K, editors. 9th Pathways of the pulp. St. Louis: Mosby Elsevier; .

4. Blattner TC, George N, Lee CC, Kumar V, Yelton CD. Efficacy of cone-beam computed tomography as a modality to accurately identify the presence of second mesiobuccal canals in maxillary first and second molars: a pilot study. J Endod. 2010;36(5):867-70. doi: 10.1016/j.joen.2009.12.023. [PubMed: 20416435]

5. Kulild JC, Peters DD. Incidence and configuration of canal systems in the mesiobuccal root of maxillary first and second molars. J Endod. 1990;16(7):311-7. [PubMed: 2081944].

6. Wolcott J, Ishley D, Kennedy W, Johnson S, Minnich S, Meyers J. A 5 yr clinical investigation of second mesiobuccal canals in endodontically treated and retreated maxillary molars. JEndod. 2005;31(4):2624. [PubMed: 15793380].

7. Gorduysus MO, Gorduysus M, Friedman S. Operating microscope improves negotiation of second mesiobuccal canals in maxillary molars. J Endod. 2001;27(11):683-6. [PubMed: 11716081]
8. Fogel HM, Peikoff MD, Christie WH. Canal configuration in the mesiobuccal root of the maxillary first molar: a clinical study. J Endod. 1994;20(3):135-7. doi: 10.1016/S0099-2399(06)80059-2. [PubMed: 7996086].

9. Stropko JJ. Canal morphology of maxillary molars: clinical observations of canal configurations. J Endod. 1999;25(6):446-50. doi: 10.1016/S0099-2399(99)80276-3. [PubMed:10530248].

10. Buhrley LJ, Barrows MJ, BeGole EA, Wenckus CS. Effect of magnification on locating the MB2 canal in maxillary molars. $J$ Endod. 2002;28(4):324-7. doi: 10.1097/00004770-200204000-00016. [PubMed: 12043874].

11. Yoshioka T, Kikuchi I, Fukumoto Y, Kobayashi C, Suda H. Detection of the second mesiobuccal canal in mesiobuccal roots of maxillary molar teeth ex vivo. Int Endod J. 2005;38(2):124-8. doi: 10.1111/j.13652591.2004.00918.x. [PubMed: 15667634].

12. Iqbal MK. Nonsurgical ultrasonic endodontic instruments. Dent Clin North Am. 2004;48(1):19-34. doi: 10.1016/j.cden.2003.10.001. [PubMed: 15066505].

13. Ozcan E, Aktan AM, Ari H. A case report: Unusual anatomy of maxillary second molar with 3 mesiobuccal canals. Oral Surg Oral Med Oral Pathol Oral Radiol Endod. 2009;107(1):e43-6. doi: 10.1016/j.tripleo.2008.09.006. [PubMed:19101482].

14. Han X, Yang H, Li G, Yang L, Tian C, Wang Y. A study of the distobuccal root canal orifice of the maxillary second molars in Chinese individuals evaluated by cone-beam computed tomography. J Appl Oral Sci. 2012;20(5):563-7. [PubMed: 23138744].

15. Vizzotto MB, Silveira PF, Arus NA, Montagner F, Gomes BP, da Silveira HE. CBCT for the assessment of second mesiobuccal (MB2) canals in maxillary molar teeth: effect of voxel size and presence of root filling. Int Endod J. 2013;46(9):870-6. doi: 10.1111/iej.12075. [PubMed: 23442087].

16. Domark JD, Hatton JF, Benison RP, Hildebolt CF. An ex vivo comparison of digital radiography and cone-beam and micro computed tomography in the detection of the number of canals in the mesiobuccal roots of maxillary molars. J Endod. 2013;39(7):901-5. doi: 10.1016/j.joen.2013.01.010. [PubMed: 23791260].

17. Cleghorn BM, Christie WH, Dong CC. Root and root canal morphology of the human permanent maxillary first molar: a literature review. J Endod. 2006;32(9):813-21. doi: 10.1016/j.joen.2006.04.014. [PubMed: 16934622].

18. Karaman GT, Onay EO, Ungor M, Colak M. Evaluating the potential key factors in assessing the morphology of mesiobuccal canal in maxillary first and second molars. Aust Endod J. 2011;37(3):134-40. doi: 10.1111/j.1747-4477.2010.00240.x. [PubMed: 22117721].

19. Omer OE, Al Shalabi RM, Jennings M, Glennon J, Claffey NM. A comparison between clearing and radiographic techniques in the study of the root-canal anatomy of maxillary first and second molars. Int Endod J. 2004;37(5):291-6. doi: 10.1111/j.0143-2885.2004.00731.x. [PubMed: 15086749].

20. Baratto Filho F, Zaitter S, Haragushiku GA, de Campos EA, Abuabara A, Correr GM. Analysis of the internal anatomy of maxillary first molars by using different methods. J Endod. 2009;35(3):337-42. doi: 10.1016/j.joen.2008.11.022. [PubMed: 19249591].

21. Weine FS, Hayami S, Hata G, Toda T. Canal configuration of the mesiobuccal root of the maxillary first molar of a Japanese subpopulation. Int Endod J. 1999;32(2):79-87. [PubMed: 10371900].

22. Imura N, Hata GI, Toda T, Otani SM, Fagundes MI. Two canals in mesiobuccal roots of maxillary molars. Int Endod J. 1998;31(6):410-4. [PubMed: 15551608].

23. Seidberg BH, Altman M, Guttuso J, Suson M. Frequency of two mesiobuccal root canals in maxillary permanent first molars. J Am Dent Assoc. 1973;87(4):852-6. [PubMed: 4516749].

24. Weller RN, Hartwell GR. The impact of improved access and searching techniques on detection of the mesiolingual canal in maxillary molars. J Endod. 1989;15(2):82-3. [PubMed: 2607274]. 
25. Sempira HN, Hartwell GR. Frequency of second mesiobuccal canals in maxillary molars as determined by use of an operating microscope: a clinical study. J Endod. 2000;26(11):673-4. doi: 10.1097/00004770200011000-00010. [PubMed: 11469299].

26. Neelakantan P, Subbarao C, Ahuja R, Subbarao CV, Gutmann JL. Conebeam computed tomography study of root and canal morphology of maxillary first and second molars in an Indian population. $J$ Endod. 2010;36(10):1622-7. doi: 10.1016/j.joen.2010.07.006. [PubMed: 20850665].

27. Sberna MT, Rizzo G, Zacchi E, Cappare P, Rubinacci A. A preliminary study of the use of peripheral quantitative computed tomography for investigating root canal anatomy. Int Endod J. 2009;42(1):66-75. doi: 10.1111/j.1365-2591.2008.01452.x. [PubMed: 18811596].

28. Zheng QH, Wang Y, Zhou XD, Wang Q, Zheng GN, Huang DM. A cone-beam computed tomography study of maxillary first permanent molar root and canal morphology in a Chinese population. $J$ Endod. 2010;36(9):1480-4. doi: 10.1016/j.joen.2010.06.018. [PubMed: 20728713].

29. Tachibana H, Matsumoto K. Applicability of X-ray computerized tomography in endodontics. Endod Dent Traumatol. 1990;6(1):16-20. [PubMed: 2390962].

30. Patel S, Dawood A, Ford TP, Whaites E. The potential applications of cone beam computed tomography in the management of endodontic problems. Int Endod J. 2007;40(10):818-30. doi: 10.1111/j.13652591.2007.01299.x. [PubMed: 17697108].

31. Liedke GS, da Silveira HE, da Silveira HL, Dutra V, de Figueiredo JA. Influence of voxel size in the diagnostic ability of cone beam tomography to evaluate simulated external root resorption. J Endod. 2009;35(2):233-5. doi: 10.1016/j.joen.2008.11.005. [PubMed:19166780].

32. da Silveira PF, Vizzotto MB, Liedke GS, da Silveira HL, Montagner F, da Silveira HE. Detection of vertical root fractures by conventional radiographic examination and cone beam computed tomography an in vitro analysis. Dent Traumatol. 2013;29(1):41-6. doi:10.1111/j.16009657.2012.01126.x. [PubMed: 22413921].

33. Azim AA, Azim KA, Deutsch AS, Huang GT. Acquisition of anatomic parameters concerning molar pulp chamber landmarks using conebeam computed tomography. J Endod. 2014;40(9):1298-302. doi: 10.1016/j.joen.2014.04.002. [PubMed: 25146010].
34. Weine FS, Healey HJ, Gerstein H, Evanson L. Canal configuration in the mesiobuccal root of the maxillary first molar and its endodontic sig nificance. Oral Surg Oral Med Oral Pathol. 1969;28(3):419-25. [PubMed: 5257186].

35. Pomeranz HH, Fishelberg G. The secondary mesiobuccal canal of maxillary molars. J Am Dent Assoc. 1974;88(1):119-24. [PubMed: 4588261].

36. Verma P, Love RM. A Micro CT study of the mesiobuccal root canal morphology of the maxillary first molar tooth. Int Endod J. 2011;44(3):210-7. doi: 10.1111/j.1365-2591.2010.01800.x. [PubMed: 20880136].

37. Smadi L, Khraisat A. Detection of a second mesiobuccal canal in the mesiobuccal roots of maxillary first molar teeth. Oral Surg Oral Med Oral Pathol Oral Radiol Endod. 2007;103(3):e77-81. doi: 10.1016/j.tripleo.2006.10.007. [PubMed: 17223589].

38. Lofthag-Hansen S, Huumonen S, Grondahl K, Grondahl HG. Limited cone-beam CT and intraoral radiography for the diagnosis of periapical pathology. Oral Surg Oral Med Oral Pathol Oral Radiol Endod. 2007;103(1):114-9. doi: 10.1016/j.tripleo.2006.01.001. [PubMed: 17178504].

39. Nakata K, Naitoh M, Izumi M, Inamoto K, Ariji E, Nakamura H. Effectiveness of dental computed tomography in diagnostic imaging of periradicular lesion of each root of a multirooted tooth: a case report. J Endod. 2006;32(6):583-7. doi: 10.1016/j.joen.2005.09.004. [PubMed: 16728257].

40. Cotton TP, Geisler TM, Holden DT, Schwartz SA, Schindler WG. Endodontic applications of cone-beam volumetric tomography.J Endod. 2007;33(9):1121-32. doi:10.1016/j.joen.2007.06.011. [PubMed: 17931947].

41. Ibarrola JL, Knowles KI, Ludlow MO, McKinley IJ. Factors affecting the negotiability of second mesiobuccal canals in maxillary molars. J Endod. 1997;23(4):236-8. doi: 10.1016/S0099-2399(97)80054-4. [PubMed: 9594773].

42. Gilles J, Reader A. An SEM investigation of the mesiolingual canal in human maxillary first and second molars. Oral Surg Oral Med Oral Pathol. 1990;70(5):638-43. [PubMed: 2234885].

43. Zhang CF, Ding RY, Yin XZ, Zhao BH, Lin QG. [Location and negotiation of second mesiobuccal canals in maxillary molars]. Zhonghua Kou Qiang Yi Xue Za Zhi. 2003;38(2):86-8. [PubMed: 12839636]. 